\title{
Development of the Neonatal Rat Small Intestinal Barrier to Nonspecific Macromolecular Absorption. II. Role of Dietary Corticosterone
}

\author{
SAUL TEICHBERG, RAUL A. WAPNIR, JEFFREY MOYSE, AND FIMA LIFSHITZ1
}

Departments of Pediatrics, Laboratories, and Research, North Shore University Hospital-Cornell University Medical College, Manhasset, New York 11030

\begin{abstract}
The role of oral corticosterone (C) in the maturation of the neonatal rat jejunal barrier to the absorption of nonspecific macromolecules was evaluated. This was done by adding $C$ to the diet of rat pups weaned at an early age, $17 \mathrm{~d}$, from maternal milk (MM) to either a protein hydrolysate (PH) or soy (S) artificial formula. Both $\mathrm{PH}$ and $\mathrm{S}$ are known to cause a delay in small intestinal closure to the absorption of a $40-\mathrm{kD}$ glycoprotein tracer, horseradish peroxidase (HRP), on d 21 of age. C was added to $\mathrm{PH}$ and $\mathrm{S}$ formulas from $\mathrm{d} 17$ to 21 at 0.26 $\mu \mathrm{mol} / \mathrm{L}(10 \mu \mathrm{g} / \mathrm{dL})$, a level found in the MM of lactating rat dams, or at $10.29 \mu \mathrm{mol} / \mathrm{L}(400 \mu \mathrm{g} / \mathrm{dL})(\mathrm{PH}+10 \mathrm{C}, \mathrm{PH}$ $+400 C)(S+10 C, S+400 C)$. Controls consisted of rat pups fed $P H$ or $S$ without $C$ and animals remaining with the dam on MM. The delay in jejunal closure to HRP on d 21 in both PH- and S-fed pups was prevented by $\mathrm{C}$ supplementation at both the higher and lower concentrations. Geometric mean (95\% confidence intervals) jejunal HRP absorption in $\mathrm{PH}+10 \mathrm{C}$ pups was $74(32,167)$ IU $\mathrm{HRP} / \mathrm{mL} \times \mathrm{cm} \times \mathrm{min}$, less than in pups fed PH without $C[353(200,615) ; p<0.05]$ and indistinguishable from HRP absorption in MM-fed animals [111 (79,154)]. HRP absorption in $\mathrm{PH}+400 \mathrm{C}$ pups $[52(23,115)]$ was also less than that in animals fed $\mathrm{PH}$ without $\mathrm{C}(p<0.01)$ and indistinguishable from those fed MM. In S-fed pups, closure delay was accompanied by a lamina propria eosinophilia not seen with $\mathrm{PH}$ or MM feedings; this did not occur in $S+400 C$ pups. Our results lend support to the view that $\mathrm{C}$, a glucocorticoid known to be present in rat $\mathrm{MM}$, may play a role in the normal ontogenetic closure of the small intestine to macromolecular absorption in the neonatal rat. (Pediatr Res 32: 50-57, 1992)
\end{abstract}
MM, maternal milk
PH, protein hydrolysate formula
$S$, soy formula
HRP, horseradish peroxidase
$C$, corticosterone
IEL, intraepithelial lymphocyte

Abbreviations

Studies from our laboratory on neonatal rat pups and work by others on the rabbit strongly suggest that normal ontogenetic closure of the small intestine of these species to macromolecular

Received April 22, 1991; accepted March 2, 1992.

Correspondence: Saul Teichberg, Ph.D., Electron Microscopy Laboratory, North Shore University Hospital, Manhasset, NY 11030.

Supported in part by PHS Grant RR05924-05.

'Present address: Department of Pediatrics, Maimonides Medical Center, Brooklyn, N.Y. absorption is dependent upon MM feedings $(1,2)$. This view is largely derived from experimental animal studies indicating that early weaning to artificial formulas delays closure. It is also consistent with data indicating the presence of numerous, potentially bioactive peptide and steroid hormones as well as trophic factors in MM that might play a role in the regulation of this process (3-9).

To establish that a specific hormone or trophic factor in MM plays a role in closure, several criteria need to be fulfilled. Addition of the putative factor to a factor-free diet that delays closure, as is seen when rat pups are weaned at an early age to artificial formulas, should normalize the timing of this process $(1,2)$. This effect should occur when the agent is delivered by a physiologic route and at a concentration found in MM. Alternatively, removal of this factor from MM should lead to a delay in the timing of closure. In the present study, we focused on the potential role of the MM glucocorticoid, C, in the closure of the neonatal rat small intestine to the absorption of macromolecules.

Earlier studies have shown that pharmacologic (intraperitoneal) administration of hydrocortisone prevents the delay in jejunal macromolecular closure in rat pups weaned at an early age to artificial formulas and induces precocious closure to IgG absorption $(1,10)$. Interpretation of previous work on the role of glucocorticoids in rat small intestinal closure has been limited by several factors including the nonphysiologic route of administration (intraperitoneal), the pharmacologic levels used, and the agent chosen, hydrocortisone, which is not the normal rat hormone $(1,3,8,9)$. The physiologic rat glucocorticoid, $\mathrm{C}$, is present in the MM of that species $(3,8,9)$. We therefore evaluated the effect of adding $\mathrm{C}$ to the diet of rat pups weaned at an early age to either $\mathrm{S}$ or $\mathrm{PH}$ formula on rat jejunal closure to a nonspecific 40-kD glycoprotein tracer, HRP.

Our data indicate that dietary $\mathrm{C}$, at a concentration reported to be present in the $\mathrm{MM}$ of nonstressed lactating rat dams [0.26 $\mu \mathrm{mol} / \mathrm{L}(10 \mu \mathrm{g} / \mathrm{dL})]$ or at a pharmacologic level $[10.26 \mu \mathrm{mol} / \mathrm{L}$ $(400 \mu \mathrm{g} / \mathrm{dL})]$, prevents the delay in a closure seen in formula-fed animals. These observations support the view that $C$ in $M M$ plays a role in the normal ontogenetic pattern of jejunal closure in the neonatal rat.

\section{MATERIALS AND METHODS}

Animals and Experimental Feedings. The experimental feeding design is outlined on Figure 1 and is based on our own previous work (1). Briefly, newborn Sprague-Dawley rat pups (Charles River, Kingston, NY) reared in litters of 12 /dam were divided on $\mathrm{d} 17$ of lactation into three groups of four pups each, from d 17 to 21 of age. One group of four pups remained with the dam and received her MM. The other groups of four rat pups each, were fed ad libitum with either S (Isomil-R) or PH (Nutramigen-R) to which we did or did not add $C$ (Sigma Chemical Co., St. Louis, MO) at a concentration of either $0.26 \mu \mathrm{mol} / \mathrm{L}(10$ 


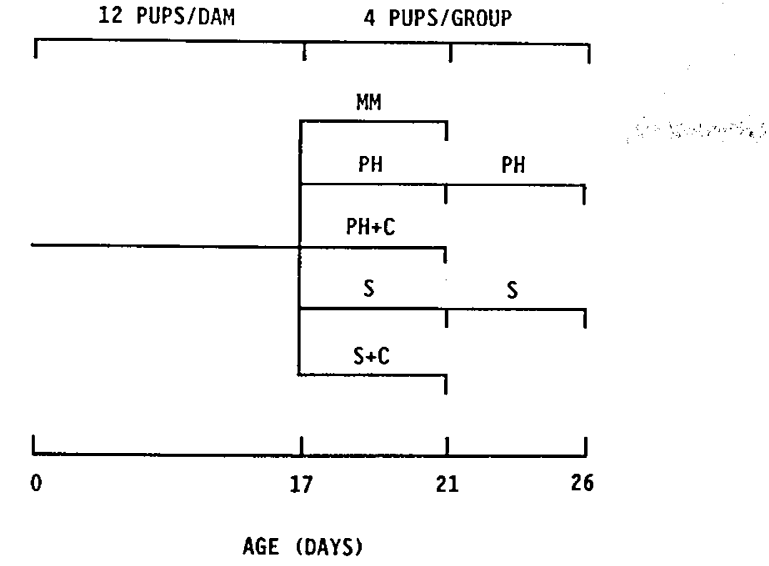

Fig. 1. Experimental feeding design. Rat pup litters were culled after birth and maintained at 12 /dam until d 17 of age. Pups from the vast majority of litters were then divided into the following feeding groups, of four animals each, from $d 17-21$ of age: maternal MM-fed, with the dam $(M M) ; \mathrm{PH} ; \mathrm{PH}+\mathrm{C}$ at $0.26 \mu \mathrm{mol} / \mathrm{L}(10 \mu \mathrm{g} / \mathrm{dL})$ or $10.29 \mu \mathrm{mol} / \mathrm{L}$ $(400 \mu \mathrm{g} / \mathrm{dL})(P H+C) ; \mathrm{S} ;$ and $\mathrm{S}+\mathrm{C}$ at $0.26 \mu \mathrm{mol} / \mathrm{L}(10 \mu \mathrm{g} / \mathrm{dL})$ or 10.29 $\mu \mathrm{mol} / \mathrm{L}(400 \mu \mathrm{g} / \mathrm{dL})(S+C)$. In other experiments, the rat pups were continually maintained on the $\mathrm{PH}$ or S diets from $\mathrm{d} 17$ to 26 , a total of $9 \mathrm{~d}(P H, P H)(S, S)$.

$\mu \mathrm{g} / \mathrm{dL})$ or $10.29 \mu \mathrm{mol} / \mathrm{L}(400 \mu \mathrm{g} / \mathrm{dL})[(\mathrm{S}+10 \mathrm{C}),(\mathrm{S}+400 \mathrm{C})$, $(\mathrm{PH}+10 \mathrm{C})$, and $(\mathrm{PH}+400 \mathrm{C})]$. $\mathrm{C}$ was used at $0.26 \mu \mathrm{mol} / \mathrm{L}(10$ $\mu \mathrm{g} / \mathrm{dL}$ ) because that is the level reported to be present in the MM of nonstressed rat dams (8). The higher dose, $10.29 \mu \mathrm{mol} / \mathrm{L}(400$ $\mu \mathrm{g} / \mathrm{dL}$ ), was chosen to compare the effect of a pharmacologic level with the lower, more physiologic concentration. There was no $\mathrm{C}$ detectable by RIA in the PH and $\mathrm{S}$ that we used. To determine whether the artificial feedings delayed closure or prevented it over more extensive periods of time, some rat pups were fed S or PH diets without C from d 17 to 26 , a total of $9 \mathrm{~d}$.

Pups were distributed into the experimental feeding groups as equally as possible by sex and weight, maintained in metabolic cages to avoid coprophagy, and provided with a folded diaper to help maintain normal body temperature. The effects of diet and $\mathrm{C}$ on weight gain were monitored. All animal experimentation was approved by the Institutional Animal Care Committee and performed within the guidelines set forth in the NIH Guide for the Care and Use of Laboratory Animals (11).

Macromolecular Absorption Studies. Small intestinal loop preparation, blood collection, serum preparation, and peroxidase activity assays were carried out as extensively detailed elsewhere $(1,12,13)$. In brief, the lumen of in situ $15-\mathrm{cm}$ jejunal loops from rat pups anesthetized with urethane $(1.3 \mathrm{~g} / \mathrm{kg})$ were washed with warm $\left(37^{\circ} \mathrm{C}\right)$ isotonic $(140 \mathrm{mM}) \mathrm{NaCl}$, equilibrated for two 30 -min periods with 1.5 -mL aliquots of $5 \mathrm{mM}$ Tris-buffered $(\mathrm{pH}$ 7.3) isotonic saline, and then filled with $1.5 \mathrm{~mL}$ of $0.125 \mathrm{mM}$ HRP (type II, $40 \mathrm{kDa}$, Sigma Chemical Co.) in isotonic buffered $\mathrm{NaCl}$ for 30 min. Loops were kept moist within the abdominal cavity with a soaked gauze pad. Rectal temperature was maintained at $36.5-38^{\circ} \mathrm{C}$ with electric heating pads throughout the procedure. At the end of the experimental period, blood $(0.40$ $0.80 \mathrm{~mL}$ ) was obtained at the lumbar bifurcation of the dorsal aorta, using a plunger-free barrel to avoid hemolysis, with a heparinized 25-gauge needle. A light straw-colored serum was prepared by spinning the blood in Wintrobe tubes at $500 \times g$ for $2 \mathrm{~h}$. Length of the perfused intestinal loops was determined with a constant $3 g$ tension.

HRP activity was assayed, with hydrogen peroxide as substrate and using $50 \mu \mathrm{L}$ of serum, by measuring the rate of change in absorbance produced by the oxidation of $o$-dianisidine in $0.1 \mathrm{M}$ phosphate buffer $(\mathrm{pH} 6.0)$ at $460 \mathrm{~nm}$ over a $1-\min$ period on a recording spectrophotometer (Shimadzu Electronics model UV160 , Tokyo, Japan) $(1,12,14)$. The data were expressed as $\mu \mathrm{mol}$ hydrogen peroxide decomposed $/(\mathrm{mL}$ serum $\times \min \times \mathrm{cm}$ loop)
$(1,12,14)$. In that range, activity is proportional to the actual concentration of HRP (12).

Morphologic Studies and Cytochemistry. HRP localization. The effects of diet and $\mathrm{C}$ on morphology were evaluated by standard light and electron microscopic cytochemical techniques as previously reported in detail $(1,12,13,15)$. Briefly, jejunal loops were fixed in situ with cold $\left(4^{\circ} \mathrm{C}\right) 2.0 \%$ glutaraldehyde in $0.05 \mathrm{M}$ cacodylate buffer $(\mathrm{pH} 7.3)$ and then rinsed several times and stored overnight in buffer with $7 \%$ sucrose. Slabs of small intestine were briefly frozen in $7.5 \%$ sucrose, rinsed in buffer, and cut perpendicular to the intestinal wall into fragments containing mucosal to serosal surfaces. The tissue fragments were then incubated for the localization of peroxidase activity for 45 min at room temperature, rinsed in cold $7.5 \%$ sucrose, postfixed in cold buffered osmium tetroxide, dehydrated in a graded series of ethanols, and embedded in effapoxy resin (Ernest F. Fullam Inc., Schenectady, NY) $(1,12,15)$. For light microscopy, welloriented $1-\mu \mathrm{m}$ plastic sections spanning the mucosal to serosal surface were evaluated unstained by phase contrast or stained with toluidine blue. Villi were then selected for study by electron microscopy. Tissue blocks were trimmed to remove the crypt zone and retain the upper half of villi with mature absorptive cells. Thin sections, lightly stained with lead citrate, were examined on a JEOL JEM 100 CX II electron microscope.

In each of the experimental feeding groups, a minimum of five rat pups were examined by light and electron microscopy. Jejunal villi evaluated morphologically came from animals fed the diets in at least three independent experiments, performed at different times. In each animal, several villi were evaluated by electron microscopy, and in all cases the sample studied was of absorptive cells in the upper half of villi, beneath the apical extrusion zone. When examining the villi under the electron microscope, the investigator was unaware of the treatment to which the animals were exposed.

To obtain more semi-quantitative data, the number of HRPfilled structures in the apical cytoplasm of absorptive epithelial cells was assessed in animals fed $\mathrm{S}$ and $\mathrm{PH}$, with or without dietary $\mathrm{C}$ supplementation. The number of HRP-containing structures was counted in sets of electron micrographs at a final magnification of $19400 \times$ and expressed as the number of HRPpositive structures $/ 100 \mu \mathrm{m}$ of linear gut lumen-apical cell surface interface. HRP-positive structures included vesicles, tubules, and multivesicular bodies. The linear lumen-apical cell surface interface was determined by tracing with an electronic pen with the aid of a Zeiss Videoplan 2 Image Analyzer (Carl Zeiss, Thornwood, NY). A minimum of 20 electron micrographs per rat and three to four rats per experimental group were used for this analysis.

Controls included loops from animals not exposed to HRP; in these preparations there was no cytochemically demonstrable peroxidase activity on microvilli or in endocytotic and lysosomal compartments. The HRP-free controls did show reaction product for endogenous peroxidases in eosinophils, neutrophils, monocytes, and erythrocytes $(1,16-18)$. The endogenous peroxidase activities were used for studies on lamina propria reactive white cell populations as detailed below.

Analysis of eosinophil, mast cell, and IEL number. The effect of diet and $C$ on the number of eosinophils, mast cells, and IEL in the lamina propria and epithelium of jejunal villi on $\mathrm{d} 21$ was evaluated. The following experimental groups were compared: $\mathrm{MM}, \mathrm{PH}, \mathrm{S}, \mathrm{S}+400 \mathrm{C}$, and $\mathrm{S}+10 \mathrm{C}$. In each group, five animals were studied and a minimum of 18 villi per rat pup were quantitatively analyzed by light microscopy using multiple samples of toluidine blue-stained $1-\mu \mathrm{m}$ plastic sections or unstained sections studied by phase contrast. Eosinophils were identified by their very large (1000-2000 $\mathrm{nm})$, phase dense, refractile, peroxidase-positive secretory granules $(1,16,17)$ (Fig. 2). Mast cells were identified by the blue staining of their large, peroxidasenegative secretory granules in toluidine blue-treated sections or by their large peroxidase-negative granules in unstained material 


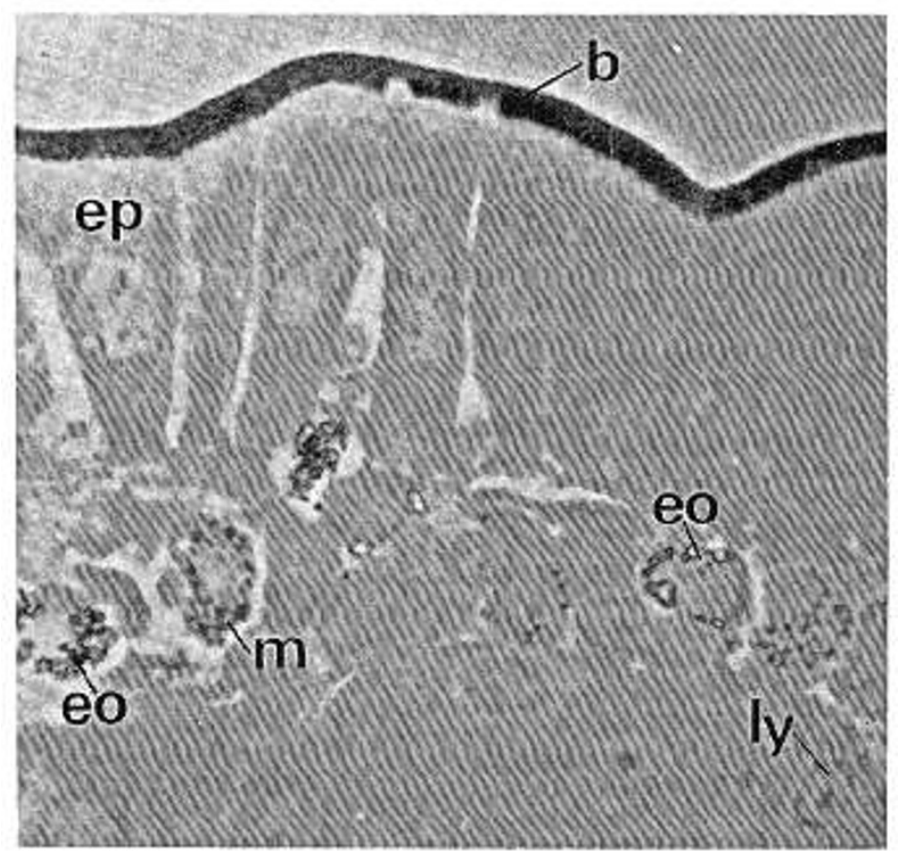

Fig. 2. Phase contrast light photomicrograph of a portion of a jejunal villus, from a rat pup fed $S$ diet from d 17 to 21 of age, exposed at the lumenal surface to HRP for $30 \mathrm{~min}$ and then incubated for the localization of peroxidase activities. Absorptive epithelial cells are at $e p$ and microvillus brush border with bound exogenous HRP is at $b$. There are several leukocytes in the lamina propria. Eosinophils $(e o)$ are identified by their large and refractile peroxidase reactive secretory granules; this eosinophilic reaction is due to endogenous peroxidase activity and is readily demonstrable in preparations not exposed to exogenous HRP $(17-19)$. Mast cells $(m)$ are identified by their large, round, secretory granules that contain no peroxidase activities (19). An intraepithelial lymphocyte $(l y)$ is present in the mucosa between absorptive epithelial cells. $\times 750$.

examined by phase contrast $(16,18)$. IEL were identified by their lack of peroxidase activity and typical lymphocyte morphologic characteristics within the epithelium of villi $(16,19)$.

Quantitative data on the number of eosinophils and mast cells in the lamina propria were expressed as number of eosinophils or mast cells/ 1000 villus epithelial cells. The number of IEL was determined and then expressed as the number of IEL/1000 villus epithelial cells. Villus epithelial cells were quantified by counting the number of mucosal epithelial cell nuclei from the villus tip to base, excluding the crypts.

Statistical Analysis. Data were analyzed by one-way analysis of variance. The threshold of significance was taken as an $F$ value with $p<0.05$ and was followed by a series of paired contrasts (20). Comparisons with controls were assessed by Dunnett's test. Comparisons between different experimental groups were by Tukey's test. When appropriate, an unpaired $t$ test was used. If arithmetic data failed to fit a normalized distribution, natural logarithm transformed data were used for statistical analyses. Data were then reexpressed as geometric means with $95 \%$ confidence intervals for descriptive statistical purposes (21).

\section{RESULTS}

Diet, Corticosterone, and Weight Gain. Rat pups fed S and $\mathrm{PH}$ weighed approximately $10 \%$ less than MM-fed animals (Table 1) (1). Although these formula-fed animals gained weight over the 4-day experimental feeding period, their weight increments were less than in MM-fed pups; MM pups gained approximately $11 \mathrm{~g}$, whereas PH- and S-fed pups gained roughly 4 and $5 \mathrm{~g}$, respectively (Table 1$)$. At the lower $0.26-\mu \mathrm{mol} / \mathrm{dL}(10-\mu \mathrm{g} /$ dL) level of C, PH-, and S-fed pups differed in their weight increments. $\mathrm{PH}+10 \mathrm{C}$ animals gained weight during the exper- imental feeding period; they showed an increment of approximately $7 \mathrm{~g}$ and could not be distinguished from 21 -d-old PH-fed pups. On the other hand, $\mathrm{S}+10 \mathrm{C}$ rat pups did not gain a significant amount of weight as compared to 17-d-old MM animals, although they were not statistically distinguishable from those fed $\mathrm{S}$ until d 21 of age. Pups fed artificial formulas with the higher $10.29-\mu \mathrm{mol} / \mathrm{L}(400-\mu \mathrm{g} / \mathrm{dL})$ level of $\mathrm{C}(\mathrm{PH}+400 \mathrm{C}$ and $\mathrm{S}+400 \mathrm{C})$ all failed to gain weight over the experimental feeding period. Both $\mathrm{PH}+400 \mathrm{C}$ and $\mathrm{S}+400 \mathrm{C}$ animals were indistinguishable in weight from 17-d-old pups, and 21-d-old $\mathrm{PH}+400 \mathrm{C}$ animals weighed less than $\mathrm{PH}$-fed pups of the same age.

Rat pups fed $\mathrm{PH}$ or $\mathrm{S}$ for a prolonged period of time, from $\mathrm{d}$ 17 to 26 , a total of $9 \mathrm{~d}$, continued to gain weight throughout that period (Table 1 ). These 26 -d-old pups gained approximately 15 $\mathrm{g}$ over their entire $9-\mathrm{d}$ experimental feeding period; $10 \mathrm{~g}$ of this weight increment occurred from d 21 to 26 of age (Table 1).

HRP Absorption: Effect of Corticosterone in PH and $S$ diets. Jejunal HRP absorption in pups fed PH for the 17- to 21-d experimental period was markedly elevated as compared with MM-fed animals. (Fig. 3). When PH diets were supplemented with $C$ at $0.26 \mu \mathrm{mol} / \mathrm{L}(10 \mu \mathrm{g} / \mathrm{dL})$ or $10.29 \mu \mathrm{mol} / \mathrm{L}(400 \mu \mathrm{g} / \mathrm{dL})$, jejunal HRP absorption was indistinguishable from that found in 21-d-old MM-fed pups and less than in 21-d-old PH-fed animals (Fig. 3).

HRP absorption in animals fed $\mathrm{S}$ was also elevated on $\mathrm{d} 21$ of age as compared to MM-fed pups (Fig. 3). Supplementation of the $\mathrm{S}$ diet with $\mathrm{C}$ at $0.26 \mu \mathrm{mol} / \mathrm{L}(10 \mu \mathrm{g} / \mathrm{dL})$ or $10.29 \mu \mathrm{mol} / \mathrm{L}$ $(400 \mu \mathrm{g} / \mathrm{dL})$ reduced jejunal HRP absorption to levels indistinguishable from those seen in MM-fed animals (Fig. 3). In animals fed S with $\mathrm{C}$ at $10.29 \mu \mathrm{mol} / \mathrm{L}(400 \mu \mathrm{g} / \mathrm{dL})$, jejunal HRP absorption was also less than in $\mathrm{S}$ pups. However, mean HRP absorption in pups fed $\mathrm{S}$ with $\mathrm{C}$ at $0.26 \mu \mathrm{mol} / \mathrm{L}(10 \mu \mathrm{g} / \mathrm{dL})$ was not distinguishable from that seen in $\mathrm{S}$ animals.

HRP Absorption: Effect of Prolonged $S$ and PH Feedings. PH and $\mathrm{S}$ feedings appear to delay closure to jejunal macromolecular absorption, but they do not prevent its eventual onset. The elevated jejunal absorption of HRP in rat pups weaned to $\mathrm{PH}$ or $S$ from d 17 to 21 was no longer apparent when the animals received these diets for a more extended period of time. HRP absorption in rat pups fed $\mathrm{PH}$ and $\mathrm{S}$ from $\mathrm{d} 17$ to $26(9 \mathrm{~d})$ was indistinguishable from that seen in MM-fed pups on d 21 (Table 2).

Diet, Corticosterone, and Villus Reactive Cells. The number of lamina propria eosinophils was increased in S-fed rat pups as compared to MM- and PH-fed animals (Fig. 4). This eosinophilia in the lamina propria of $S$-fed animals was suppressed in pups fed S with $\mathrm{C}$ at $10.29 \mu \mathrm{mol} / \mathrm{L}(400 \mu \mathrm{g} / \mathrm{dL})$ but was unaltered in animals fed $\mathrm{S}$ with $\mathrm{C}$ at $0.26 \mu \mathrm{mol} / \mathrm{L}(10 \mu \mathrm{g} / \mathrm{dL})$. In PH-fed rat pups, lamina propria eosinophil numbers were similar to those in MM-fed animals. There was no effect of diet or $\mathrm{C}$ on lamina propria mast cell number or on villus IEL (Fig. 4).

Diet, Corticosterone, and Absorptive Epithelial Cell Morphology. Light microscopy. Enzyme cytochemical studies suggest that $\mathrm{C}$ supplementation prevents the diffusion of HRP across altered epithelial cells in 21-d-old S-fed rat pups (1). In S-fed animals, the number of villus absorptive epithelial cells stained with diffuse cytoplasmic reaction product for HRP was decreased by supplementation of the diet with $\mathrm{C}$ at either $0.26 \mu \mathrm{mol} / \mathrm{L}(10$ $\mu \mathrm{g} / \mathrm{dL}$ ) or $10.29 \mu \mathrm{mol} / \mathrm{L}(400 \mu \mathrm{g} / \mathrm{dL}$ ) (Fig. $5 a$ and $b$ ). In S-fed animals, there were $8.8 \pm 2.2$ diffusely stained villus absorptive epithelial cells $/ 10$ villi; in $\mathrm{S}+10 \mathrm{C}$ there were $4.3 \pm 1.1(p<$ 0.05 versus $S$ ) and in $S+400 C, 3.9 \pm 1.5(p<0.05$ versus $S)$. These diffusely stained cells were generally restricted to small numbers of villi, whereas in the majority of villi HRP was only found on the microvillus brush border. Overall villus architecture appeared unaffected by diet or $C$ supplementation at either a high or low level. Villi in 21-d-old rat pups weaned to $\mathrm{S}$ or $\mathrm{PH}$ diets with or without $\mathrm{C}$ were indistinguishable from those in MM-fed animals; there was no evidence of villus shortening or excess sloughing of epithelial cells. 
Table 1. Effect of diet and corticosterone on rat pup weight*

\begin{tabular}{|c|c|c|c|c|c|c|}
\hline $\begin{array}{l}\text { Age } \\
\text { (d) }\end{array}$ & $n$ & Diet & Weight $(\mathrm{g})$ & $\begin{array}{c}p \text { vs } 17 \\
\text { MM }\end{array}$ & $\begin{array}{c}p \text { vs } 21 \\
\mathrm{MM}\end{array}$ & $\begin{array}{c}p \text { vs } 21 \mathrm{~S} \\
\text { or } \mathrm{PH}\end{array}$ \\
\hline 17 & 42 & $\mathrm{MM}$ & $40.5+0.4$ & & 0.01 & 0.05 \\
\hline 21 & 40 & $\mathrm{MM}$ & $51.4 \pm 0.8$ & 0.01 & & 0.01 \\
\hline 21 & 15 & $\mathrm{PH}+10 \mathrm{C}$ & $47.8 \pm 1.0$ & 0.05 & NS & NS \\
\hline 21 & 16 & $\mathrm{PH}+400 \mathrm{C}$ & $39.6 \pm 0.9$ & NS & 0.01 & 0.01 \\
\hline 21 & 40 & $S$ & $44.1 \pm 0.6$ & 0.05 & 0.01 & \\
\hline 26 & 12 & $\mathrm{PH}$ & $54.5 \pm 2.5$ & 0.01 & NS & 0.01 \\
\hline 26 & 10 & $\mathrm{~S}$ & $55.1 \pm 3.7$ & 0.01 & NS & 0.01 \\
\hline
\end{tabular}

* Data are means \pm SEM. PH+10C, PH $+0.26 \mu \mathrm{mol} \mathrm{C} / \mathrm{L}$ formula $(10 \mu \mathrm{g} \mathrm{C} / \mathrm{dL}) ; \mathrm{S}+10 \mathrm{C}, \mathrm{S}+0.26 \mu \mathrm{mol} \mathrm{C} / \mathrm{L} \mathrm{formula}(10 \mu \mathrm{g} \mathrm{C} / \mathrm{dL}) ; \mathrm{PH}+400 \mathrm{C}$, $\mathrm{PH}+10.29 \mu \mathrm{mol} \mathrm{C} / \mathrm{L}$ formula $(400 \mu \mathrm{g} \mathrm{C} / \mathrm{dL}) ; \mathrm{S}+400 \mathrm{C}, \mathrm{S}+10.29 \mu \mathrm{mol} \mathrm{C} / \mathrm{L}$ formula $(400 \mu \mathrm{g} \mathrm{C} / \mathrm{dL})$.

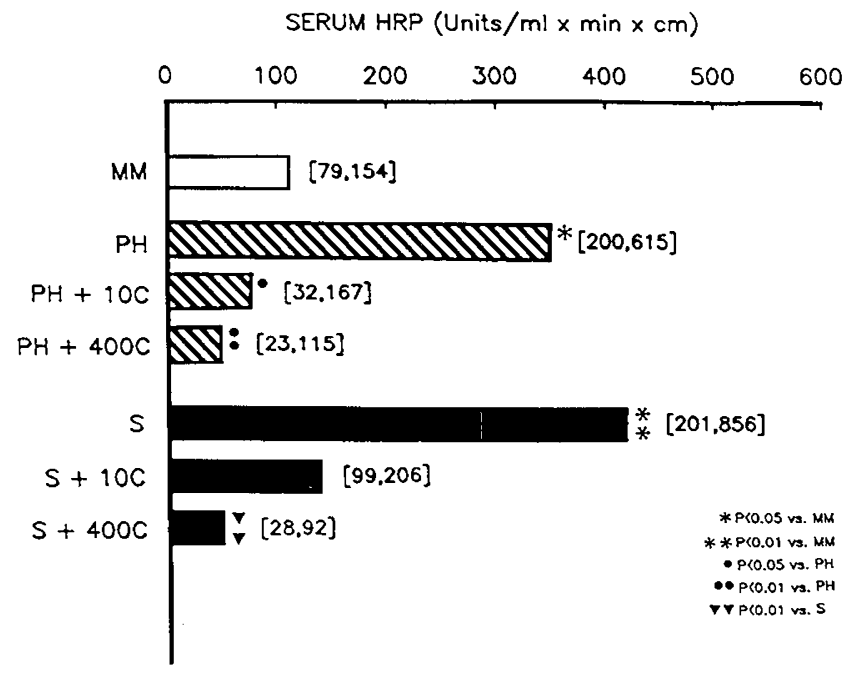

Fig. 3. Effect of $\mathrm{C}$ supplementation on jejunal absorption of HRP in 21-d-old neonatal rat pups fed either artificial $\mathrm{PH}$ or $\mathrm{S}$ from $\mathrm{d} 17$ to 21 of age. Bars represent geometric means, with $95 \%$ confidence intervals in brackets. The delay in jejunal closure to HRP absorption in PH- and $\mathrm{S}$-fed rat pups as compared with MM-fed animals is prevented by dietary supplementation with $\mathrm{C}$ at $0.26 \mu \mathrm{mol} / \mathrm{L}(10 \mu \mathrm{g} / \mathrm{dL})(P H+10 C ; S+$ $10 C)$ and $10.29 \mu \mathrm{mol} / \mathrm{L}(400 \mu \mathrm{g} / \mathrm{dL})(P H+400 C ; S+400 C)$. In both $\mathrm{PH}+10 \mathrm{C}$ and $\mathrm{PH}+400 \mathrm{C}$ rat pups, jejunal HRP absorption was indistinguishable from that found in $\mathrm{MM}$ animals and less than in $\mathrm{PH}-$ fed pups. In $S+10 C$ and $S+400 C$ rat pups, HRP absorption was indistinguishable from that seen in MM animals; however, HRP absorption was less than in S-fed pups only with $S+400 C$.

Table 2. Jejunal absorption of HRP in rat pups on extended feedings of $P H$ and $S^{*}$

\begin{tabular}{clrcc}
\hline $\begin{array}{c}\text { Age } \\
(\mathrm{d})\end{array}$ & Diet & $n$ & $\begin{array}{c}\text { HRP absorbed } \\
\text { [Geom. mean (95\% C.I.)] } \dagger\end{array}$ & p vs 21-d MM \\
\hline 21 & MM & 26 & $111(79,154)$ & \\
26 & PH & 7 & $52(26,105)$ & NS \\
26 & S & 8 & $70(24,201)$ & NS \\
\hline
\end{tabular}

* Rat pups were maintained on either PH or S diets from d 17 to 26 of age. Units of HRP absorbed are expressed as $\mu \mathrm{mol}$ hydrogen peroxide decomposed $/ \mathrm{mL}$ serum $\times \min \times \mathrm{cm}$ intestine. Statistical analysis was by one-way analysis of variance of natural logarithm transformed data, with paired comparisons vs 21-d MM rat pups by Dunnett's test.

$\dagger$ Geometric mean and $95 \%$ confidence interval.

Electron microscopy. We evaluated the localization of HRP in jejunal absorptive epithelial cells of 21-d-old rat pups found in the upper half of the villi beneath the apical cell extrusion zone. The addition of $\mathrm{C}$ to $\mathrm{S}$ and $\mathrm{PH}$ diets appeared to decrease transport of HRP across the epithelium and into the basolateral intercellular space. In S- and PH-fed animals, HRP was demonstrable on the microvillus brush border, in small numbers of endocytotic vesicles, tubules, and multivesicular bodies, and, at times, in the intercellular space between absorptive cells (Fig. $6 a$ ). By contrast, when the $\mathrm{S}$ and $\mathrm{PH}$ diets were supplemented with C, HRP was almost never seen in the intercellular space between absorptive cells (Fig. $6 b$ ). The number of HRP-filled structures in the apical cytoplasm of jejunal absorptive epithelial cells in PH-fed animals was greater than that in $\mathrm{PH}$-fed pups supplemented with $\mathrm{C}$, at both the lower $(0.26 \mu \mathrm{mol} / \mathrm{L})(10 \mu \mathrm{g} /$ $\mathrm{dL})$ and the higher level of C [10.29 $\mu \mathrm{mol} / \mathrm{L}(400 \mu \mathrm{g} / \mathrm{dL})]$. Values are the mean number of HRP-filled structures/100 $\mu \mathrm{m}$ linear gut lumen-cell interface \pm SEM: $\mathrm{PH}, 25 \pm 2$ versus $\mathrm{PH}+10 \mathrm{C}$, $10 \pm 3(p<0.05$ versus $\mathrm{PH}) \mathrm{PH}+400 \mathrm{C}, 8 \pm 3(p<0.01$ versus $\mathrm{PH})$. In S-fed animals, only the higher level of C $[10.29 \mu \mathrm{mol} / \mathrm{L}$ $(400 \mu \mathrm{g} / \mathrm{dL})]$ led to a decrease in the number of HRP-positive structures in absorptive cells $[\mathrm{S}, 23 \pm 7$ versus $\mathrm{S}+10 \mathrm{C}, 15 \pm 3$; ( $p$ NS versus $\mathrm{S}) ; \mathrm{S}+400 \mathrm{C}, 11 \pm 1(p<0.05$ versus $\mathrm{S})]$.

There was no evidence of $\mathrm{C}$-induced ultrastructural alterations in jejunal absorptive epithelial cells. Organelles in epithelial cells of animals fed low or high levels of C-supplemented $\mathrm{PH}$ or $\mathrm{S}$ diets were indistinguishable from those in PH-, S-, and MM-fed pups.

\section{DISCUSSION}

Although many hormones and trophic factors are present in MM, their physiologic roles remain largely obscure (3-7). The present study lends support to the hypothesis that the MM glucocorticoid, C, plays a role in the normal development of jejunal closure to the absorption of nonspecific macromolecules in the neonatal rat. Alternatively, the effect of dietary $\mathrm{C}$ on rat jejunal closure to HRP could be due to the amelioration of direct or immune-mediated damage induced by the formulas we used or to a pharmacologic action of the glucocorticoid on absorptive cell maturation.

Physiologic considerations. Our data fulfill some criteria necessary to establish $\mathrm{C}$ as a physiologic agent regulating the normal ontogenetic closure of the neonatal rat small intestine. The view that $\mathrm{C}$ added to artificial diets acts by a physiologic mechanism, preventing the delay in closure in artificial formula-fed animals by replacing glucocorticoid normally delivered via MM, is supported by several observations. In our study, $C$ in the diet is effective at a level reported to be present in the MM of nonstressed lactating rat dams $(3,8)$. Therefore, we believe it is unlikely that these data are merely the result of a pharmacologic effect of the steroid. It has been suggested that the experimental route and timing of hormone delivery, particularly in relation to agents found in MM, bears upon the relevance to normal events 


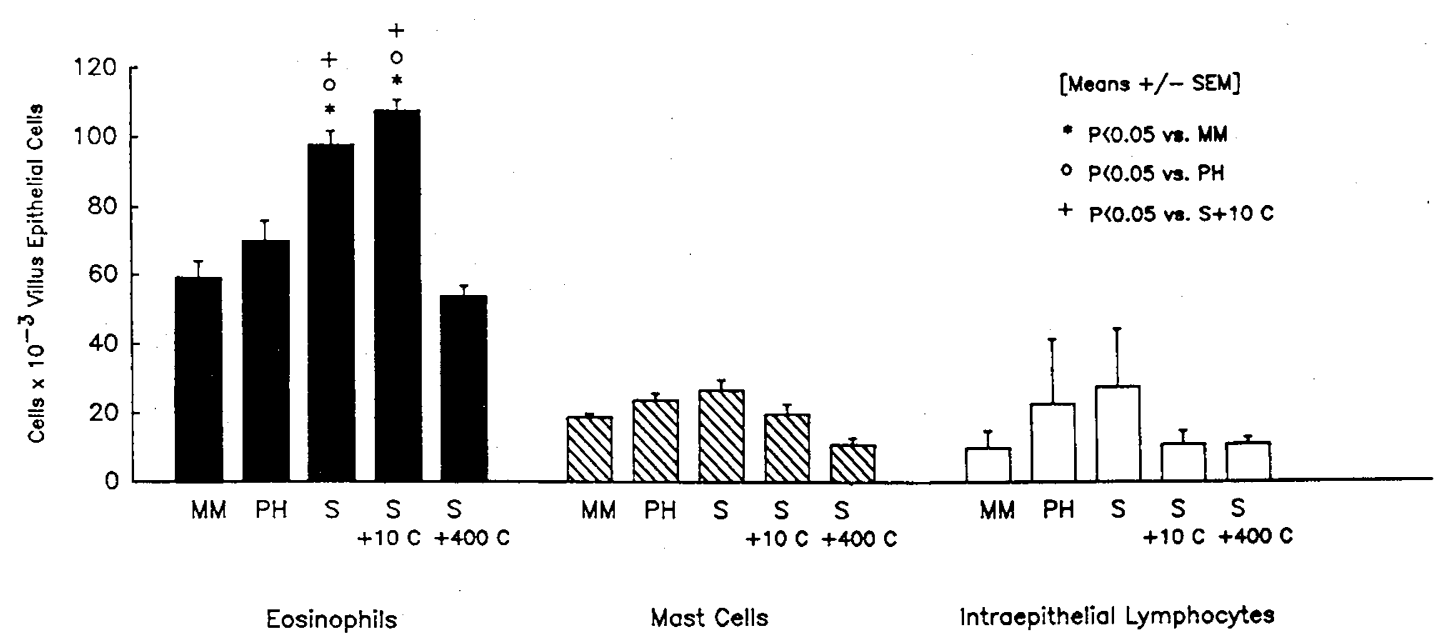

Fig. 4. Effect of diet and C supplementation on the number of eosinophils, mast cells, and intraepithelial lymphocytes in jejunal villi of 21-d-old neonatal rat pups. Pups fed S from d 17 to 21 of age showed increased numbers of lamina propria eosinophils compared to MM- or PH-fed animals. This eosinophilia was suppressed by supplementation of the $\mathrm{S}$ diet with $\mathrm{C}$ at $10.29 \mu \mathrm{mol} / \mathrm{L}(400 \mu \mathrm{g} / \mathrm{dL})(+400 C)$ but not by $\mathrm{C}$ at $0.26 \mu \mathrm{mol} / \mathrm{L}(10$ $\mu \mathrm{g} / \mathrm{dL})(+10 \mathrm{C})$. The number of eosinophils was unaffected by PH feeding. There was no detectable effect of diet or C on the number of mast cells or intraepithelial lymphocytes.
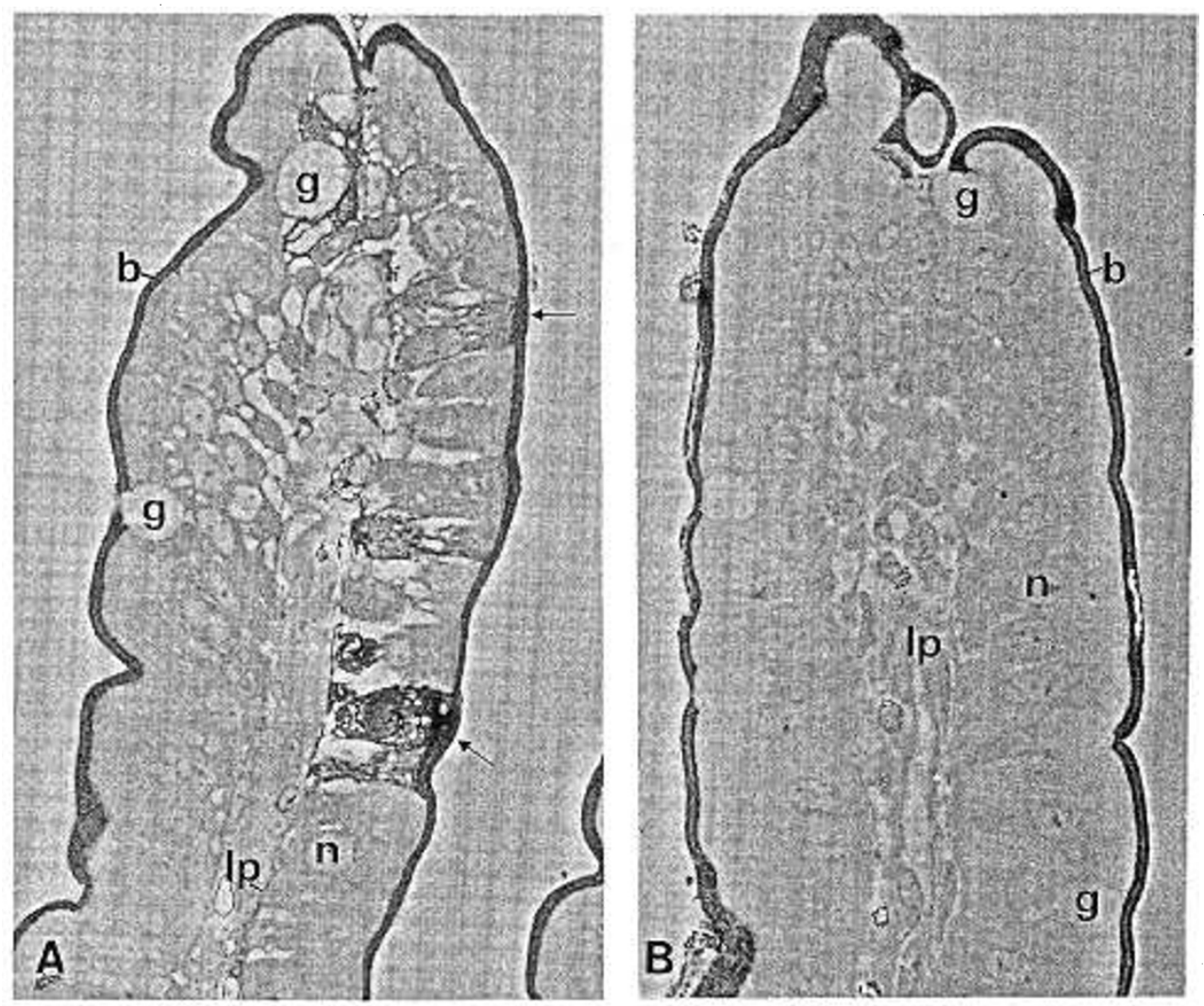

Fig. 5. Phase contrast light photomicrographs of jejunal villi from 21 -d-old rat pups fed either $\mathrm{S}$ alone $(A)$ or $\mathrm{S}$ supplemented with $\mathrm{C}$ at 10.29 $\mu \mathrm{mol} / \mathrm{L}(400 \mu \mathrm{g} / \mathrm{dL})(B)$ from d 17 to 21 of age and then exposed to luminal HRP for $30 \mathrm{~min}$. In A, reaction product for HRP is seen on the brush border $(b)$, in several diffusely stained absorptive epithelial cells (arrows), and in the lamina propria ( $1 p$ ). In $\mathrm{B}$, from a C-supplemented, S-fed rat pup, HRP is restricted to the brush border $(b)$. Nuclei are at $n$, goblet cells at $g . A, \times 275 ; B, \times 275$.

(7). In the present work, C was administered orally, ad libitum, in the diet. This is a mode of delivery resembling the manner in which pups receive glucocorticoid from the dam in MM.

The normalization of the development of closure by $\mathrm{C}$ in rat pups weaned to a $\mathrm{PH}$ is not likely to be due to an amelioration of possible damage to the jejunum produced by the diet. Earlier, we demonstrated that $\mathrm{PH}$ feeding does not lead to structural damage to the absorptive epithelial cells that would allow diffusion of macromolecules across an altered brush border, but did provide evidence for vesicle mediated transport across the epi- thelium (1). The present study supports the view that the delay in closure in PH-fed rat pups is not due to immune-mediated damage to the mucosa; in PH-fed pups, there was no evidence of local effector cell proliferation like that which may be seen during an antigen sensitizing response $(22,23)$. It should be noted that PH contains low molecular weight (200 to 1200-D) constituents is considered hypoallergenic, even in patients with a genetic predisposition for the development of atopic disease $(24,25)$. Earlier studies on the neonatal rabbit also suggested that artificial formula-induced closure delay was not 

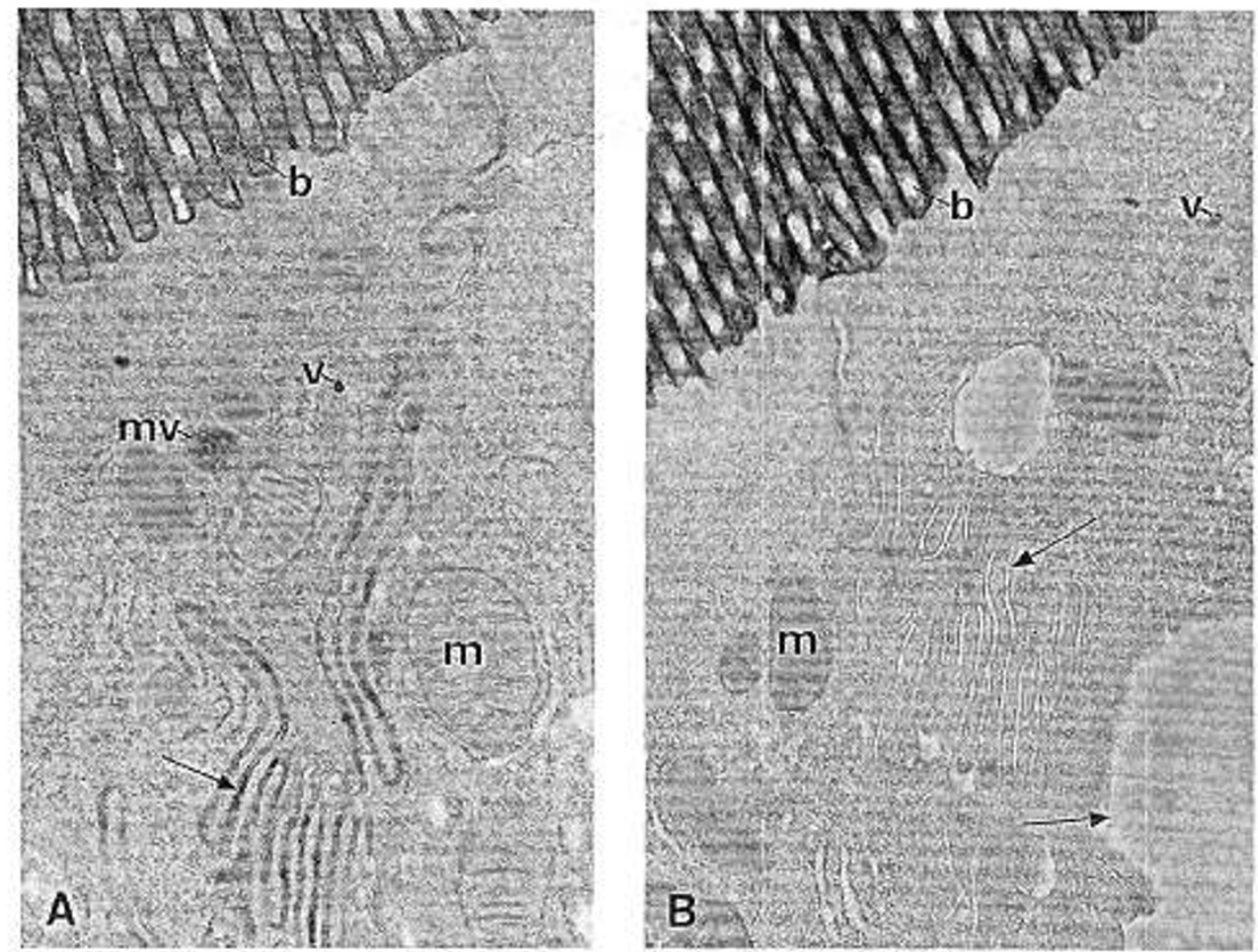

Fig. 6. Electron micrographs of portions of jejunal absorptive epithelial cells from the upper half of villi of 21-d-old rat pups fed either $S$ alone (A) or S supplemented with $\mathrm{C}$ at $0.26 \mu \mathrm{mol} / \mathrm{L}(10 \mu \mathrm{g} / \mathrm{dL})(B)$ and then exposed to luminal HRP for $30 \mathrm{~min}$. In A, HRP is seen on the microvillus brush border $(b)$, in a small number of endocytotic vesicles $(v)$, in a multivesicular body $(m v)$, and in the intercellular space between the epithelial cells (arrows). In B, from the C-supplemented, S-fed rat pup, HRP is found on the microvillus brush border $(b)$ and in a small apical vesicle $(v)$. HRP is not seen in the intercellular space between the epithelial cells (arrows). Mitochondria are at $m . A, \times 26000 ; B, \times 26000$.

due to direct or immune-related damaging agents (2). These observations, and the apparent decrease in endocytosis induced by $\mathrm{C}$ in $\mathrm{PH}$-fed animals, support the view that the delay in closure in PH-fed rat pups is mediated by vesicular transport of intact macromolecules from the mucosal to serosal surface of the epithelium (1).

The decline in HRP absorption in rat pups fed $\mathrm{PH}$ or $\mathrm{S}$ for more prolonged periods of time, d $17-26$ of age, indicates that closure is delayed but not abolished by weaning to artificial formulas. Therefore, the requirement for $\mathrm{C}$ in $\mathrm{MM}$ does not appear to be absolute. As in the intestinal differentiation pattern of disaccharidases linked to glucocorticoid action, the role of $\mathrm{C}$ in MM during the final events of closure may be one of controlling rate and time (26).

The mechanism by which $\mathrm{C}$ in $\mathrm{MM}$ might play a role in regulating the timing of closure in the neonatal rat is unclear. $\mathrm{C}$ may directly affect the mucosa, contribute to an elevation of serum $\mathrm{C}$, or exert its action indirectly in concert with other hormones or trophic factors $(3,7,26)$. Corticosteroids have been reported to exert stabilizing effects on lysosomal and other membrane systems (27). Thus, dietary C might alter the fluidity of microvillus as well as other membrane systems. This could affect closure by altering either endocytosis or fusions between endocytotic vesicles and other cell membrane compartments, including the basolateral plasma membrane, thereby preventing transport of macromolecules across the epithelium. Although apparently reduced in number, some HRP-filled vesicles were seen in the apical cytoplasm of absorptive cells of $C$-supplemented animals. However, transport of HRP into the intercellular space between the cells was almost never demonstrable, suggesting that $\mathrm{C}$ might in part mediate its effects on vesicle membrane fusion; clearly, this requires further study. It is important to reemphasize that the amount of endocytosis seen at the apical surface of absorptive epithelial cells is very dramatically higher on $\mathrm{d} 17$ than on $\mathrm{d} 21$. This is true regardless of the diet; 21 -d-old PH- and S-fed animals resemble 21-d-old MM-fed animals to a much greater degree than they do 17-d-old pups (1).

Further studies on the regulatory events involved in the dramatic transformation of the endocytotic apparatus of the absorptive epithelium during the $4 \mathrm{~d}$ before weaning in the neonatal rat would be of great interest. As we have previously noted, the number of HRP-filled vesicles and other structures in jejunal absorptive epithelial cells is markedly less in 21-d-old than in 17$\mathrm{d}$-old animals, regardless of the diet (1). Some histologic data in concert with kinetic studies of intestinal cell renewal time and studies of IgG receptor phenotypes of villus epithelial cells have been interpreted as suggesting that closure in the neonatal rat involves the replacement of highly endocytic cells by a new population of epithelial cells with much lower levels of endocytosis that arise in the crypts $(26,28-30)$. Such a mechanism has been implicated for the development of sucrase-isomaltase activity in the rat intestine (26). Whether the decline in absorption of nonspecific macromolecules such as HRP involves a similar discrete phenotypic switch or a gradual decline in endocytosis within each absorptive cell still remains to be determined. It would be important to determine the delaying effect of artificial diets or the accelerating effect of $\mathrm{C}$ on this process, and these studies would be of great interest.

Studies on the effect of luminal versus systemic glucocorticoid delivery have been very limited. Some data from adrenalectomized pups suggests that precocious enzyme maturation induced by $\mathrm{C}$ is mediated by a systemic route, even when the agent is delivered intraluminally (31).

Additional work is required to more firmly establish the view that $\mathrm{C}$ in $\mathrm{MM}$ plays a physiologic role in the regulation of closure in the neonatal rat. For example, we need to demonstrate that feeding of $\mathrm{MM}$ from which $\mathrm{C}$ has been specifically removed will result in a delay or prevention of closure. It is also important to recognize that virtually nothing is known about the possible effects of other hormonal trophic agents in MM, including 
bioactive peptides such as epidermal growth factor, on the ontogenesis of closure $(3,5,7)$. Clearly, these observations in the altricial neonatal rat on the dramatic decline in endocytosis in association with closure must be carefully distinguished from the modest decline in macromolecular absorption found in neonatal human infants $(32,33)$.

Pathophysiologic considerations. In addition to its possible physiologic role, $\mathrm{C}$ in S-fed animals may prevent some pathophysiologic effects of the diet on closure. Previously, we reported that S-induced closure delay in the neonatal rat is also associated with evidence of damage to the microvillus brush border of jejunal absorptive cells, leading to diffusion of HRP across increased numbers of epithelial cells (1). The present study suggests that this damage may in part be due to an immune-mediated lamina propria eosinophilia, which can occur during a sensitizing response $(22,34-37)$. However, the lamina propria eosinophilia found in S-fed animals was only inhibited by a high level of dietary $\mathrm{C}$, whereas $\mathrm{C}$ at a level found in rat MM normalized closure without suppressing the jejunal eosinophilia.

As we have previously reported, control weight-matched studies strongly suggest that a modest developmental weight deficit, per se, is not sufficient to produce a delay in jejunal closure in formula-fed rat pups (1). This is supported by our current data indicating that pups supplemented with high levels of $\mathrm{C}$ weigh less than any of the other experimental groups but show a normal maturation of closure.

Clinical considerations. In this study, we used neonatal rat pups during the last $4 \mathrm{~d}$ before the day when the animals were weaned. Pups at this age are relatively mature and able to survive independently of the dam (1). Nevertheless, several important caveats must be borne in mind when comparing observations on closure in the altricial neonatal rat, born at a stage of very immature intestinal development, and the more precocial human infant. In the rat, neonatal macromolecular absorption mediates essential physiologic events: receptor-mediated endocytosis of $\mathrm{IgG}$ and trophic factors, as well as nonspecific uptake for nutrition $(3,4,7,32,38)$. Closure in the rat is associated with a dramatic decline of endocytosis $(1,32)$. Despite the beneficial effects of human milk feeding, the uptake of macromolecules from human breast milk does not appear to be essential for normal development $(32,33,39)$. Although studies on antigen absorption from formulas and human milk support the view that closure occurs in human infants, the amount of uptake appears to be at a lower level than in the rat and neonatal human closure appears to be a much less dramatic event $(32,33,39)$. Evidence suggests that vesicle-mediated macromolecular absorption in humans is prominent at the mid-gestational fetal stage, whereas neonatal absorption reflects the persistence of this earlier process; this is also compatible with the apparently higher level of uptake in preterm as compared to full-term infants $(32,33,39)$.

Nevertheless, the glucocorticoid cortisol is present in human milk at a somewhat lower concentration than C in rat MM (40). Further studies are required to explore the view that glucocorticoids, or other hormonal trophic factors present in milk, play a role in the maturation of closure in human infants.

Acknowledgment. The authors thank Marni Gaines for her very valuable technical assistance with the animal studies.

\section{REFERENCES}

1. Teichberg S, Isolauri E, Wapnir RA, Roberts B, Lifshitz P 1990 Development of the neonatal rat small intestinal barrier to nonspecific macromolecular absorption: effect of early weaning to artificial diets. Pediatr Res 28:31-37

2. Udall JN, Colony P, Fritze L, Pang K, Trier JS, Walker WA 1981 Development of gastrointestinal mucosal barrier. II. The effect of natural versus artificial feeding on intestinal permeability to macromolecules. Pediatr Res 15:245249

3. Koldovsky O, Thornburg W 1987 Hormones in milk. J Pediatr Gastroenterol Nutr 6:172-176
4. Weaver LT, Walker WA 1988 Epidermal growth factor and the developing human gut. Gastroenterology 94:845-847

5. Berseth CL 1987 Enhancement of intestinal growth in neonatal rats by epidermal growth factor in milk. Am J Physiol 253:G662-G665

6. Berseth CL, Michener SR, Nordyke CK, Vay Liang WG 1990 Postpartum changes in pattern of gastrointestinal regulatory peptides in human milk. Am J Clin Nutr 51:985-990

7. Koldovsky O 1989 Search for role of milk borne biologically active peptides for the suckling. J Nutr 119:1543-1551

8. Yeh K-Y 1984 Corticosterone concentrations in the serum and milk of lactating rats: parallel changes after induced stress. Endocrinology 115:1364-1370

9. Kliewer RL, Rasmussen KM 1987 Malnutrition during the reproductive cycle: effects on galactopoetic hormones and lactational performance in the rat. Am J Clin Nutr 46:926-935

10. Borthistle BK, Kubo RT, Brown WR, Grey HM 1977 Studies on receptors for IgG on epithelial cells of the rat intestine. J Immunol 119:471-476

11. Guide for the Care and Use of Laboratory Animals 1985 NIH Publication no. 85-23, Bethesda, MD

12. Teichberg S, McGarvey E, Bayne MA, Lifshitz F 1983 Altered jejunal macromolecular barrier induced by alpha dihydroxy deconjugated bile salts. Am $\mathrm{J}$ Physiol 245:G122-G132

13. Teichberg S, Wapnir RA, Zdanowicz M, Roberts B, da Costa Ribeiro H, Lifshitz F 1989 Morphologic and functional alterations in absorptive epithelial cells during L-tryptophan induced inhibition of net sodium and fluid absorption in the rat ileum. Lab Invest 60:88-101

14. Steinman RM, Cohn ZA 1972 The interaction of soluble horseradish peroxidase with mouse peritoneal macrophages in vitro. J Cell Biol 55:186-204

15. Cooper M, Teichberg S, Lifshitz F 1978 Alterations in rat jejunal permeability to a macromolecular tracer during a hyperosmotic load. Lab Invest 38:447454

16. Cline MJ 1975 The White Cell. Harvard University Press, Cambridge, MA,

17. Hyman PM, Teichberg S, Starrett S, Vinciquerra V, Degnan TJ 1978 Secretion of primary granules from developing human eosinophilic promyelocytes. Proc Soc Exp Biol Med 159:380-385

18. Bentfeld ME, Nichols BA, Bainton DF 1977 Ultrastructural localization of peroxidase in leukocytes of rat bone marrow and blood. Anat Rec 187:219225

19. Cummins AG, Steele TW, La Brooy JT, Shearman DJC 1986 Maturation of the rat small intestine at weaning: changes in epithelial cell kinetics, bacterial flora and mucosal immune activity. Gut 29:1672-1679

20. Bruning JL, Kintz BL 1977 Computational Handbook of Statistics, 2nd Ed. Scott Foresman, Glenview, IL

21. Gardner MJ, Altman DG 1986 Confidence intervals rather than P values: estimation rather than hypothesis testing. $\mathrm{Br}$ Med $\mathbf{J}$ [Clin Res] 292:746-750

22. Powell GK 1988 Gastrointestinal manifestations of food allergy. In: Chiarmonte LT, Schneider AT, Lifshitz F (eds) Food Allergy. Marcel Dekker, New York, pp 213-229

23. Barrett KE, Metcalf DD 1988 Immunologic mechanisms in food allergy. In: Chiaramonte LT, Schneider AT, Lifshitz F (eds) Food Allergy. Marcel Dekker, New York, pp 23-43

24. Moses NS 1988 Hypoallergenic formulas. In: Chiaramonte LT, Schneider AT, Lifshitz F (eds), Food Allergy. Marcel Dekker, New York, pp 453-464

25. Chandra RK, Singh G, Shridhara B 1989 Effect of feeding whey hydrolysate, soy and conventional cow milk formulas on incidence of atopic disease in high risk infants. Ann Allergy 63:102-106

26. Henning S 1987 Functional development of the gastrointestinal tract. In: Johnson IR (ed) Physiology of the Gastrointestinal Tract, 2nd Ed. Raven Press, New York, pp 285-300

27. Holtzman E 1989 Lysosomes. Plenum Press, New York

28. Leece JG, Broughton CW 1973 Cessation of uptake of macromolecules by neonatal guinea pig, hamster and rabbit intestinal epithelium (closure) and transport into blood. J Nutr 103:744-750

29. Clark RM, Hardy RN 1969 An analysis of the mechanism of cessation of uptake of macromolecular substances by the intestine of the young rat ("closure"). J Physiol (Lond) 204:127-134

30. Rodewald R 1980 Distribution of immunoglobulin $G$ receptors in the small intestine of the young rat. J Cell Biol 85:18-32

31. Yeh K-Y, Yeh M, Holt PR 1989 Induction of intestinal differentiation by systemic and not by luminal corticosterone in adrenalectomized rat pups. Endocrinology 124:1898-1904

32. Weaver LT, Walker WA 1989 Uptake of macromolecules in the neonate. In: Lebenthal E (ed) Human Gastrointestinal Development. Raven Press, New York, pp 731-748

33. Axelsson I, Jakobsson I, Lindberg T, Polberger S, Benediktsson B, Raiha N 1989 Macromolecular absorption in pretern and term infants. Acta Paediatr Scand 78:532-537

34. Bloch KJ, Walker WA 1981 Effect of locally induced intestinal anaphylaxis on the uptake of a bystander antigen. J Allergy Clin Immunol 67:312-216 
35. Ament ME, Rubin CE 1972 Soy protein: another cause of the flat intestinal lesion. Gastroenterology 62:227-234

36. Powell GK 1978 Milk and soy induced enterocolitis of infancy. J Pediatr 93:553-560

37. Kagnoff MF 1987 Immunology of the digestive system. In: Johnson LR (ed) Physiology of the Gastrointestinal Tract, 2nd Ed. Raven Press, New York, pp 1699-1728

38. Patt JA 1977 Factors affecting the duration of intestinal permeability to macromolecules in newborn animals. Biol Rev Cambridge Philosophic Soc $52: 411-429$

39. Eastham EJ, Lichauco T, Grady MI, Walker WA 1978 Antigenicity of infant formulas: role of immature intestine on protein permeability. J Pediatr 93:561-564

40. Kulski JK, Hartmann PE 1981 Changes in the concentration of cortisol in milk during different stages of human lactation. Aust J Exp Biol Med Sci 59:769-780 